Artigo de Reflexáo/Ensaio

\title{
Terapia ocupacional e o direito à cidade
}

\section{Occupational therapy and right to the city}

\author{
Ricardo Lopes Correia $^{\mathrm{a}}$ (D), Monica Villaça Gonçalves ${ }^{\mathrm{b}}$ (D) \\ ${ }^{a}$ Universidade Federal do Rio de Janeiro - UFRJ, Rio de Janeiro, RJ, Brasil.

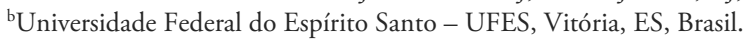

Como citar: Correia, R. L., \& Gonçalves, M. V. (2021). Terapia ocupacional e o direito à cidade. Cadernos Brasileiros de Terapia Ocupacional, 29, e2757. https://doi.org/10.1590/2526-8910.ctoARF2082

\begin{abstract}
$\underline{\text { Resumo }}$
Este ensaio tem como objetivo apresentar reflexôes sobre a terapia ocupacional na garantia do "direito à cidade" como um direito humano e social fundamental, diretamente relacionado com as ocupaçôes humanas. Iniciamos este debate com as ocupaçôes coletivas enquanto determinantes na construção do espaço social das cidades. Em seguida, focalizamos as assimetrias do poder e as desigualdades territoriais, frutos da mercantilização da propriedade urbana, que implicam injustiças e privaçôes no envolvimento ocupacional no cotidiano dos sujeitos. Sumarizamos possibilidades teórico-metodológicas, novas e outras já conhecidas, que trazemos à luz das questôes urbanas, e que aproximam a terapia ocupacional do campo dos estudos urbanos e das políticas públicas de urbanização. Defendemos que a terapia ocupacional é uma área de significativas contribuiçóes na defesa e garantia do direito à cidade.
\end{abstract}

Palavras-chave: Terapia ocupacional, Liberdade de Circulação, Urbanização, Planejamento de Cidades.

\section{$\underline{\text { Abstract }}$}

This essay aims to reflect on Occupational Therapy in guaranteeing the "right to the city" as a fundamental human and social right, directly involved in human occupations. We started this debate with collective occupations as determinants in the construction of the social space of cities. Then, we focus on the asymmetries of power and territorial inequalities, fruits of the commercialization of urban property, which imply injustices and deprivations in occupational involvement in the subject's daily lives. We summarize theoretical and methodological possibilities, new and others already, that we bring to the field of urban studies and public urbanization policies. We defend that Occupational Therapy is an area of significant contributions to the defense and guarantee of the right to the city.

Keywords: Occupational Therapy, Freedom of Movement, Urbanization, City Planning. 


\section{Introduçáo}

O campo dos estudos urbanos é histórica e tradicionalmente produzido por aportes teórico-metodológicos da Arquitetura e Urbanismo, Geografia e da Sociologia (Correia, 2019b). No entanto, trata-se de um espaço técnico-epistêmico poroso o suficiente para a inserção de outras áreas que se interessam pela vida nas cidades (Gehl \& Svarre, 2018) e, portanto, objeto de análise e compreensão complexa da realidade, que deve, de forma emergente, atender à açáo interdisciplinar (Rolnik, 1995). Assim, este ensaio ganha corpo no sentido de "alargar as bases epistêmicas da terapia ocupacional" (Costa \& Alves, 2017), ao propor perspectivas que balizam a produçáo de saberes e práticas na área, com base nas questōes urbanas e no direito à cidade.

Para tanto, iniciamos este debate com as ocupaçóes coletivas enquanto determinantes na construção do espaço social das cidades. Em seguida, focalizamos as assimetrias do poder e as desigualdades socioterritoriais, frutos da mercantilização da propriedade urbana, que implicam injustiças e privaçóes no envolvimento ocupacional cotidiano dos sujeitos sociais. Por fim, sustentamos a afirmativa de que a terapia ocupacional é uma área de significativas contribuições na defesa e garantia do direito à cidade. Para isso, sumarizamos um quadro de possibilidades que aproximam a terapia ocupacional do campo dos estudos urbanos e das políticas públicas de urbanização, que estruturam e dinamizam as questóes da cidade, e ordenam as respostas para o seu enfrentamento.

Em tela, existem distintos eixos epistêmicos para compreender a estrutura do objeto de conhecimento e intervenção da terapia ocupacional, que expóem uma complexa arena de narrativas em disputas no cenário nacional e global (Galheigo et al., 2018). O nosso posicionamento é o do objeto como o "envolvimento ocupacional, de indivíduos e coletivos, nas atividades da vida cotidiana”. Este envolvimento compreende a relação indissociável do sujeito com o seu ambiente e a construção temporal, cotidiana, estruturada por meio da realização de atividades, a fim de que estas possam promover bem-estar e participação social (Law, 2002; Silva \& Oliver, 2019; Sobel, 1993; Vessby \& Kjellberg, 2010).

Dada a amplitude dos estudos sobre a ocupação humana, aqui, focaliza-se naqueles que propóem uma perspectiva crítica, que, de acordo com Galheigo (2012), compreende uma leitura complexa do fenômeno, considerando os diversos determinantes históricos, sociais, culturais e políticos, a fim de evitar verdades absolutas e análises superficiais. Neste sentido, o construto "ocupaçôes coletivas" (Ramugondo \& Kronenberg, 2015) apresenta forte convergência com o objetivo deste debate, em especial, sobre a formação e dinâmicas do espaço social.

Portanto, o nosso objetivo é convidar a categoria para um debate a respeito de uma perspectiva técnico-epistêmica da terapia ocupacional no campo das questóes urbanas, que valorizem as compreensóes sobre a vida cotidiana nas cidades e, com isso, promover teorias, processos e tecnologias para delinear açôes práticas e pesquisas na área.

\section{As Ocupaçóes Humanas na Produção do Espaço Social das Cidades}

Historicamente, a representação ocidental da "ocupação" esteve atrelada ao significado do trabalho alienado (Constantinidis, 2012). No entanto, os estudos sobre a ocupação humana a modificaram ao longo do tempo (Reed et al., 2013), e, sob perspectivas históricas mais críticas (Huff et al., 2020) e descolonizadoras (Simaan, 2020), centralizaram a ocupação nos processos da terapia ocupacional, enquanto um fenômeno histórico, social e culturalmente construído. Desta forma, nesses estudos, a ocupação é 
compreendida como uma dimensão do fazer humano, que colabora com a compreensão e explicação sobre a experiência humana, por meio da relação indissociável entre sujeitocontexto/ambiente, assim como oferece suporte para as práticas terapêutico-ocupacionais.

Neste sentido, "ocupação humana" não se opõe a "atividade", muito menos a "cotidiano", e serve para designar um eixo epistêmico de estudos (Hammell, 2009; Ramugondo et al., 2015). Por esta razão, ocupação não pode ser tratada como um conceito isolado, e, sim, como uma categoria que expóe distintas representaçóes mentais/sociais e quadros epistêmicos, construídos na esteira dos processos sociais, históricos, culturais e políticos que se relacionam aos interesses da terapia ocupacional (Christiansen, 1994).

Pelo exposto, as ocupaçóes colaboram para a produção e expressão das identidades, para a sustentaçáo da vida prática, material e simbólica, bem como para os processos complexos de inclusão e participação social (Galvaan, 2015). Neste sentido, pensamos em uma terapia ocupacional que produz conhecimentos sobre estratégias, processos e tecnologias para promover, apoiar e facilitar o envolvimento ocupacional (Law, 2002) de sujeitos que enfrentam dificuldades de se inserir socialmente nas atividades da vida cotidiana, e que, portanto, podem experimentar a ausência de oportunidades de exercer, com autonomia e interdependência, a cidadania e o bemestar por meio de suas capacidades ocupacionais. Por este ângulo, os elementos que conformam o fenômeno ocupação humana permitem uma leitura da realidade complexa do cotidiano e do tecido social (Kantartzis \& Molineux, 2017), que implicam facilitadores e barreiras (Tolvett, 2016), para a participação nas diversas esferas da vida nas cidades.

Sobre isso, uma das perspectivas que se interseccionam ao debate é a das "ocupações coletivas" (Ramugondo \& Kronenberg, 2015). Estas compreendem o envolvimento coletivo de sujeitos em ocupaçóes relacionadas à produção e à dinâmica do espaço social. Todo sujeito só pode ser lido dentro da vida humana, quando significado por e pelo pertencimento em sua comunidade. Portanto, as ocupaçóes coletivas são, para além das formas ocupacionais, a intencionalidade do envolver-se coletivamente, compreendendo um agir que implica forças, papéis, habilidades, capacidades e compartilhamento de significados em situaçóes mutuamente identificadas para a coesão e/ou disjunção do tecido social (Kantartzis \& Molineux, 2017). Com base nesta leitura, a cidade pode ser compreendia como um tecido social constituído por ocupaçóes que propiciam o envolvimento coletivo.

Nos estudos urbanos, a cidade é uma dimensão territorial formada pelas condiçóes da geografia física, e pelas "atividades humanas" " que coletivamente as pessoas se envolvem (Serpa, 2007). A cidade, nesta concepção, compõe a imersão territorial do agir coletivo, e que, portanto, manifesta-se em estruturas e dimensóes relacionadas à convivência, à sociabilidade, ao lazer, ao trabalho, à mobilidade, entre outras (Rolnik, 1995). Estas manifestaçóes são mediadas e suportadas por estruturas e equipamentos, como as vias urbanas, os meios de transporte, os edifícios, a iluminação, os parques e praças, o mobiliário urbano, entre outros. Assim, a cidade é uma dimensão ocupacional, ou seja, um espaço social produzido pela territorialidade física, que oferece suporte para os sujeitos realizarem atividades, as quais, a partir do compartilhamento de seus significados, cumprem a função de estruturar e dinamizar os processos de sociabilidade, convivência e participação social.

\footnotetext{
${ }^{1}$ Serpa (2007), assim como Rolnik (1995), utilizam a expressão atividade humana para definir cidade. No entanto, os autores nâo fazem menção do referencial teórico que suporta tal compreensão. Aliás, isso parece uma lacuna nos estudos urbanos, como demonstrados por Gehl (2018). De qualquer maneira, esta expressão se aproxima do nosso entendimento de ocupação, conforme já apresentado neste ensaio.
} 
Desta forma, entendemos que a tomada de consciência, sobre os mecanismos da questão urbana que implicam o envolvimento ocupacional, contribui com o poder de governança dos sujeitos, aumentando o engajamento no agir coletivo e as transformaçóes locais - trata-se, portanto, da coesão do tecido social. Por outro lado, a sua disjunção compreende o envolvimento ocupacional que ameaça a participação social. Esta, segundo Kantartzis \& Molineux (2017), vulnerabiliza e rompe com as redes de oportunidades ocupacionais, impedindo que os sujeitos sejam capazes de reconhecer o poder da intencionalidade e do exercício coletivo para as transformaçóes locais.

Contudo, as oportunidades para o envolvimento ocupacional nas cidades é uma arena de assimetrias e injustiças, que capturam a participação social enquanto uma das configuraçôes da "questão urbana" (Castells, 2006). Esta questão compreende, segundo o autor, as desigualdades socioterritoriais, que traduzem, sob muitas configuraçóes e expressóes na vida cotidiana das cidades, o efeito da mercantilização do solo urbano, tomado como propriedade na sociedade neoliberalista.

\section{Assimetrias do poder e desigualdades socioterritoriais: A produçáo das injustiças e a privaçáo dos direitos sociais no envolvimento ocupacional na cidade}

As cidades brasileiras são diversas e desiguais. Estas são frutos dos distintos processos de uso e apropriaçáo do espaço territorial e de sua (in)capacidade de gestão e governança. Tratase de processos que remontam a colonizaçáo jesuítica e exploratória dos europeus à dependência político-econômica globalizada do capitalismo atual, que regem os modelos de desenvolvimento das cidades (Castells, 2006). Conforme argumentam Harvey (2012) e Léfebbre (2001), a questão urbana compreende ainda um sistema de operações de produção e manutenção da segregaçáo social que orienta tais modelos. Estes estáo centrados no interesse e poder do capital econômico - o que colabora para a fragmentação e precarização dos espaços, dada a inversáo do valor de uso pelo valor de troca da cidade. Igualmente, Santos (2007) defende que esta formação do espaço social das cidades, sobretudo na América Latina, é regida por protocolos de dependência política e econômica posta pelos países dominantes; acentuando o uso de poderes atrelados ao capital econômico para definir o ordenamento do solo urbano, a partir da distribuição injusta das atividades cotidianas.

Sob estas considerações, não podemos deixar de destacar que o Brasil é um território continental diverso, e que possui 5.570 municípios (Instituto Brasileiro de Geografia e Estatística, 2010) que vivenciam extremas desigualdades político-econômico-sociais. A dificuldade com que determinados municípios enfrentam os seus problemas de vida local reflete não só a insuficiente máquina administrativa, mas também a histórica disputa e controle dos territórios por grupos majoritários de interesse econômico, que marcam, de forma violenta, as políticas de governo (Instituto de Pesquisa Econômica Aplicada, 2015). Tais grupos se relacionam às organizações criminosas e à especulação imobiliária, ambas associadas ou revestidas de Estado. Observamos nas favelas, em cidades como o Rio de Janeiro e São Paulo, a precarização das condiçóes de moradias da população mais vulnerável, muitas vezes geridas pelo tráfico e pela milícia, que se consolidam como um governo local, frente à ausência do Estado.

Sobre isso, Rolnik (2019) apresenta a categoria "trabalho-moradia" para deflagrar, superar e explicar uma das configuraçóes da questão urbana relacionada à ideia de "centroperiferia”, enquanto simples divisão dicotômica da desigualdade socioterritorial. Para a 
autora, essa categoria, na verdade, emoldura as trajetórias de habitabilidade precária dos mais pobres no espaço social das cidades e as situaçóes de violência às quais estáo submetidos. Os mais pobres materializam a sua vida cotidiana na cidade, a partir daquilo que fazem entre o local de trabalho e a residência. Como nem sempre as oportunidades entre um e outro se encontram disponíveis e equiparáveis, os mais pobres se sujeitam a viver a cidade de forma precária e limitada nas "franjas" dos centros urbanos, reduzindo as suas experiências de lazer, de alimentação digna e saudável, de estruturas urbanas de qualidade e eficácia, entre outros, para garantir alguma proximidade entre o trabalhar e o morar, mitigando a pauperização e o tempo dispendido na orquestração de suas atividades. Os mecanismos públicos e políticos para equalizar tais desigualdades são a criação e a implementação de modelos em desenvolvimento local, mas que, baseados na lógica neoliberalista, transformam cidadáos em consumidores.

Neste sentido, as cidades são intencionalmente projetadas para estruturar sistemas de distribuição de atividades, condicionando os envolvimentos ocupacionais em zonas de interesse do capital (Serpa, 2007). Isso, por um lado, assegura a determinados grupos sociais a permanência em espaços das cidades, como nas áreas de interesse social para a construção de conjuntos habitacionais, mas, por outro, reforça a destinação dos mais pobres às zonas de baixa infraestrutura (Fernandes, 2005; Fernandes \& Alfonsin, 2016; Santos, 2007), expondo-os, como já exemplificado, à habitabilidade precária entre "trabalho-moradia". Tal sistema de iniquidade reforça as injustiças de usar e habitar a cidade, especialmente quando esta passou a se "modernizar" e a oferecer melhores condiçóes estruturais e econômicas, o que se configura como uma contradição, pois, como argumenta Harvey (2012), mais liberdade terá na cidade quem puder pagar por ela. Trata-se, portanto, de questões que implicam a emergência por um sistema de proteção social, via políticas públicas, que, no caso brasileiro, ainda se mostra insuficiente.

Contudo, mesmo que a realidade dos municípios brasileiros ainda retrate desigualdades socioterritoriais, é importante destacar que foi com a promulgação da Constituição Federal de 1988 que, pela primeira vez no país, os municípios foram nomeados como entidades federativas da união, e, portanto, passaram a ter autonomia e personalidade jurídica para legislar e executar políticas públicas a nível municipal. Isso possibilitou, além de uma relação menos hierarquizada com o governo federal, uma gestão mais atenta à realidade local e efetiva às respostas de suas demandas. Desse modo, sob a natureza cidadã da Constituição, decorrente do processo de retomada da democracia política do Brasil, a cidade passou a ser considerada um direito social fundamental e, portanto, a unidade mínima (local) da gestão territorial democrática (Freitas \& Bueno, 2018; Kirzner, 2006).

\section{O direito à cidade e as políticas públicas de urbanizaçáo}

Léfebvre (2001), com base em uma recapitulação da história das cidades ocidentais europeias, entendeu que a cidade é um produto histórico das relaçóes humanas. Logo, se elas mudam, a cidade também muda. $\mathrm{O}$ autor afirma que, com a consolidação da cultura do consumo e dos processos de industrialização advindos da intensificação do sistema capitalista, o espaço citadino passou de um local de participação na vida social e comunitária para um local que mercantiliza as trocas de bens e de lugares. Para ele, em resistência aos efeitos capitalista da cidade, o direito à cidade, termo que cunhou em sua obra, inclui a participação e a sua apropriação aos "[...] locais de encontros e de trocas, aos ritmos de vida e emprego do tempo 
que permitam o uso pleno e inteiros desses momentos e locais" (Léfebvre, 2001, p. 139). Tratase de "direito à vida urbana transformada" (Léfebvre, 2001), que só seria possível por meio de uma revoluçáo do modo de produção capitalista, uma vez que esse modo leva à segregação social, que, na visão desse autor, destrói as cidades e ameaça a vida urbana. Por sua vez, David Harvey, seguindo a mesma perspectiva teórica, diz que o direito à cidade é "[...] o direito de mudar a nós mesmos pela mudança da cidade" (Harvey, 2012, p. 74).

Já Trindade (2012) compreende que tais determinaçóes impostas pelo sistema capitalista se mostram, talvez, pouco prováveis à mudança de uma "revolução" que vise à sua "extinção", apostando mais em uma perspectiva de reconfiguração do sistema capitalista. Assim, o autor destaca a importância das recentes políticas públicas urbanas, como dispositivos de dissoluçáo das assimetrias e injustiças produzidas no espaço social das cidades. Desta forma, o autor não ignora a importância da leitura filosófica do direito à cidade, ao contrário, defende que esta deve fundamentar e orientar a ação jurídicoinstitucional, por meio dos instrumentos de gestão democrática no cotidiano das cidades.

$\mathrm{Na}$ esteira destas questôes, Harvey (2012) afirma que o direito à cidade é o "[...] exercício de um poder coletivo de moldar o processo de urbanização" (Harvey, 2012, p. 74). Com isso, o direito à cidade tem sido utilizado amplamente por diversos movimentos sociais no Brasil, para pautar o acesso a direitos sociais em diversas dimensóes da vida social. $\mathrm{O}$ início dessa pauta pode ser localizado na década de 1960, a partir das reinvindicaçóes do Movimento Nacional pela Reforma Urbana - MNRU (Saule Júnior \& Uzzo, 2009). A organização desse movimento conseguiu incluir na Constituição Federal de 1988 dois capítulos sobre Política Urbana (capítulos 182 e 183), que culminaram mais tarde na instituição do Estatuto das Cidades (Brasil, 2001) e na criação do Ministério das Cidades, em $2003^{2}$.

$\mathrm{O}$ Estatuto da Cidade tem como objetivo orientar as diretrizes e instrumentos para o ordenamento e desenvolvimento das cidades, a fim de promover o bem-estar e a cidadania, assim como preservar o meio ambiente (Brasil, 2001). Para além da concepçáo de desenvolvimento como um processo exclusivamente econômico, o Estatuto propóe a concepçáo de desenvolvimento como gestão democrática da cidade, e, portanto, assegurando a condição e obrigatoriedade da participaçáo social na condução de seus instrumentos de gestáo. Para tanto, o Estatuto define o plano diretor participativo (PDP) como o instrumento básico para planejar e ordenar a cidade, devendo ser implementado pelo gestor público municipal, a partir da nomeação de um comitê gestor e do envolvimento de diversos segmentos sociais (Brasil, 2001). Tais instrumentos legislativos incluem, na gestão urbana, a participação de diversos atores interessados nesta discussão, possibilitada pelas Conferências Nacionais das Cidades e do Conselho Nacional das Cidades $^{3}$ (Cafrune, 2016; Secretaria Municipal de Direitos Humanos e Cidadania, 2015), que asseguram o "exercício do poder coletivo" enquanto direito à cidade.

\section{Açóes da Terapia Ocupacional no Campo Interdisciplinar das Questóes Urbanas}

A cidade é um campo complexo que exige lentes epistêmicas diversas para compor leituras da realidade e a consequente resposta interdisciplinar às suas demandas relacionadas

\footnotetext{
${ }^{2}$ A partir da atual gestão do Governo Federal, em 2019, o Ministério da Cidade foi destituído e rebaixado à secretaria do novo Ministério do Desenvolvimento Regional, com caráter exclusivamente econômico.

${ }^{3}$ Importante destacar que, desde o início do atual governo presidencial, os Conselhos e Comitês da Cidade foram suspensos, assim como de outras políticas públicas. Diversos movimentos sociais pela Reforma Urbana reivindicam o retorno destes, como assegura a Constituição Federal, mas até a escrita deste ensaio o cenário se mostra pouco favorável.
} 
à garantia do direito à cidade (Rolnik \& Pinheiro, 2004). Acreditamos, neste sentido, que uma oportunidade para identificar e construir um lugar propositivo da terapia ocupacional no campo dos estudos e das práticas urbanas é articular as questóes do objeto profissional às macrossociais do espaço social das cidades. Portanto, a atenção sobre o envolvimento ocupacional das pessoas na vida das cidades é um caminho oportuno para sanar, como denuncia Gehl \& Svarre (2018), as lacunas do que o fazer cotidiano das pessoas reflete no planejamento do espaço urbano (Correia et al., 2017), bem como na produçáo de bemestar e participação social.

Dadas as considerações, sumarizamos, na sequência, alguns construtos teóricometodológicos, nos quais assimilamos a área de terapia ocupacional e o direito à cidade.

\section{Abordagem da Terapia Ocupacional de Ensinagem em Desenvolvimento Local Participativo (TO/EDLP)}

A abordagem de TO/EDLP (Correia, 2018b) possui enquanto objetivo envolver grupos socialmente distintos em projetos coletivos para operar mudanças no contexto de vida local, a fim de fomentar a gestáo do território e o poder local de seus agentes. Esta se estrutura em quatro procedimentos: I) imersão; II) mapeamento das percepçóes da realidade; III) rodas de conversa e; IV) projetos de vida coletiva. Os procedimentos oferecem pistas para a criação e exploração de estratégias comunitárias de ensino-aprendizagem, nas quais os agentes locais tomam decisóes e se envolvem coletivamente para modificar aspectos negativos de seu contexto local.

As experiências identificadas com o uso da abordagem de TO/EDLP (Correia, 2018a, 2019a; Correia et al., 2016, 2018, 2017; Correia \& Akerman, 2015) sinalizam uma íntima relação com as questôes que envolvem a produção do espaço social e o direito à cidade, uma vez que a aplicação da abordagem vem sendo utilizada em contextos de revisóes e criaçóes de planos diretores participativos, valorizando os processos comunitários, em especial junto a populaçóes historicamente apartadas da participação social das políticas urbanas. A abordagem de TO/EDLP foi criada em 2011, no contexto de projetos de extensão universitária, e segue em desenvolvimento e validação também em projetos de consultoria a municípios de pequeno e médio porte do Brasil (Correia, 2017). A abordagem, portanto, ao promover a participação social de agentes locais nas demandas de seus territórios, colabora com o direito à cidade.

\section{Acessibilidade Cultural}

Desde 2009, o departamento de terapia ocupacional da Universidade Federal do Rio de Janeiro oferece a Especialização Lato Sensu em "Acessibilidade Cultural”, a fim de formar multiplicadores desta pauta em todas as regiōes do Brasil (Dornelles et al., 2018). Apoiada em um paradigma estético, a Acessibilidade Cultural insere uma mudança cognitiva sobre o modo de compreender as estruturas, composiçóes e dinâmicas da sociabilidade e convivência, e, portanto, interferindo nos modos de produzir cultura nos espaços sociais da cidade (Correia, 2019b). Assim, as açóes, projetos e estratégias em Acessibilidade Cultural, que, pensadas inicialmente para os ambientes culturais, ampliam-se para a cidade, e transbordam o acesso e a participação para todas as pessoas (Sarraf, 2018). 
Desta forma, projetos em terapia ocupacional que tomam a Acessibilidade Cultural como um paradigma estético (Dorneles \& Lopes, 2016) podem desenvolver conhecimentos e práticas, a partir do Desenho Universal, Tecnologia Assistiva, Comunicação Alternativa e Aumentativa, Políticas Culturais, Arte e Desenvolvimento Local. As açóes podem compreender a acessibilidade nos equipamentos culturais enquanto dispositivos de fruição cultural e, portanto, de direito da população em vivenciar a cidade, tanto nos contextos de fruição cultural institucionais, como museus, teatros, quanto nos de produçáo cultural de base comunitária e territorial, como os pontos de cultura, manifestaçóes populares e eventos festivos, entre outros, que sáo ocupaçóes coletivas que fazem parte da identidade e memória da cidade (Correia, 2019b).

\section{Tecnologia Assistiva}

Terapeutas ocupacionais já estão, há bastante tempo, inseridos na área de Tecnologia Assistiva (TA). No entanto, chamamos atenção sobre a necessidade de superar a TA como área destinada exclusivamente ao campo clínico da reabilitação. Os dispositivos, métodos e recursos em TA, pensados a partir das demandas do envolvimento ocupacional dos sujeitos na vida das cidades, podem colaborar com estratégias e projetos de planejamento urbano (Cassapian \& Rechia, 2014; Cavalcanti et al., 2013; Ferreira et al., 2013; Gomes \& Emmel, 2016) e, com isso, equalizar as desigualdades socioterritoriais, vivenciadas por grupos historicamente negligenciados nas políticas urbanas, como as pessoas com deficiência, idosos, pessoas analfabetas, entre outros.

A terapia ocupacional, neste sentido, pode contribuir com os órgãos de planejamento urbano, como secretarias, treinando pessoal técnico, bem como na assessoria e educaçáo da população com deficiência e sem deficiência, idosos, e, sobretudo, no planejamento, indicação e avaliação dos dispositivos de TA para equipamentos urbanos, sejam eles arquitetônicos, metodológicos ou comunicacionais.

Neste sentido, propóe-se também um alargamento dos modelos e abordagens de terapia ocupacional na área de TA que superem a lógica individualizante das avaliaçóes e prescriçóes, e dimensione-as em contextos da coletividade, desenvolvendo protocolos, manuais e instrumentos, com base na noção de acessibilidade média para o acesso e participação coletiva em ambientes públicos, como dispóe a Lei Brasileira de Inclusão (Brasil, 2015). Para isso, além das dimensóes arquitetônicas, é essencial que terapeutas ocupacionais saibam analisar as ocupaçóes da cidade, considerando seus aspectos metodológicos e comunicacionais, ou seja, como a cidade funciona, o estabelecimento de seus signos e estratégias de funcionamento e emissão de informaçóes. Portanto, terapeutas ocupacionais podem ser protagonistas em elevar a TA para o status de direito social e tecnologia social ao relacioná-la às políticas urbanas acessíveis e à sua implementação efetiva na vida das cidades.

\section{Mobilidade urbana cotidiana}

A mobilidade urbana é uma atividade humana por natureza e é essencial ao modo de vida dos sujeitos, fazendo parte de seus cotidianos (Balbim, 2016). Esse conceito se debruça sobre as problemáticas sociais e permite inseri-lo como um elemento importante na prática 
em terapia ocupacional (Gonçalves, 2020; Gonçalves \& Malfitano, 2021). Define-se mobilidade urbana cotidiana como:

uma prática social, definida pelos significados, impactos e representaçóes dos deslocamentos e movimentos cotidianos de pessoas e coletivos pelo espaço urbano. Ela ocorre no cotidiano, marcada e influenciada pela posiçáo social dos sujeitos, caracterizando-se como imprescindível para a sua participação social e efetivação da cidadania. Engloba as transformaçóes sociais relacionadas ao movimento pela cidade e às significaçóes dos deslocamentos para a vida de pessoas e grupos, incluindo suas causas e consequências (Gonçalves, 2020, p. 319)

Gonçalves (2020) aponta que a discussão da mobilidade urbana cotidiana na terapia ocupacional pode se dar com base em quatro dimensóes: I) objetivo específico da intervenção; II) forma/instrumento de avaliação em terapia ocupacional; III) recurso da prática para se atingir o objetivo proposto e; IV) conceito/referência para fundamentar a inserção da profissão na discussão das políticas públicas de planejamento urbano. As reflexôes sobre a mobilidade urbana cotidiana têm se mostrado fértil para nós, por se referirem à defesa do direito à cidade por parte da terapia ocupacional, assim como no debate interdisciplinar sobre a temática (Gonçalves \& Malfitano, 2020; Gonçalves et al., 2020; Vieira Filho et al., 2020).

\section{Consideraçóes Finais}

A cidade, para além de um cenário ou pano de fundo, é um campo de questóes que implica envolvimentos ocupacionais sustentados por territórios de oportunidades assimétricas, o que gera desfechos ambíguos de justiça e injustiça, coesão e disjunção, em torno do direito à cidade. Por isso, acreditamos que a cidade é um campo de estudo e práticas sociais interdisciplinares emergentes para a terapia ocupacional.

Para captar esta emergência, elegemos, neste ensaio, os estudos da ocupação humana como um eixo epistêmico, que reúne distintas perspectivas teóricas e conceituais sobre a experiência humana na relação com os contextos/ambientes. Este eixo nos ajudou, e vem ajudando, sobretudo pela perspectiva conceitual das ocupaçóes coletivas, a articular aportes da área disciplinar com as macroquestóes e ferramentas dos estudos urbanos.

O espaço social das cidades é onde as pessoas produzem e compartilham as suas ocupaçóes, que são as unidades máximas de análise e intervenção da realidade complexa e interdisciplinar, servindo como lente e sistema de comunicação específica da área. Desta forma, a terapia ocupacional precisa tecer relaçóes mais próximas com aportes teóricopráticos dos Estudos da Ocupaçáo Humana, da Sociologia, Antropologia, Geografia, Urbanismo, Arquitetura e Políticas Públicas Sociais, para alargar e significar o seu próprio objeto de conhecimento e colaborar com os enfrentamentos das barreiras que dificultam a participação social dos sujeitos na cidade.

Por fim, esperamos que terapeutas ocupacionais se interessem pela vida das cidades e que possam colaborar com estudos e desenvolvimento de políticas urbanas, assim como na busca de soluçóes práticas para problemas locais. $\mathrm{O}$ conhecimento produzido por redes interdisciplinares contribui de forma mais efetiva e eficiente para o desenvolvimento da sociedade e a produção de meios que garantam o direito à cidade. 


\section{Referências}

Balbim, R. (2016). Mobilidade: uma abordagem sistêmica. In R. Balbim, C. Krause \& C. C. Linke (Orgs.), Cidade e Movimento. Mobilidades e Interaçôes no Desenvolvimento Urbano (pp. 23-42). Brasília: IPEA.

Brasil. (2001, 10 de julho). Lei no 10.257, de 10 de julho de 2001. Regulamenta os arts. 182 e 183 da Constituição Federal, estabelece diretrizes gerais da política urbana e dá outras providências. Diário Oficial [da] República Federativa do Brasil, Brasília.

Brasil. (2015, 6 de julho). Lei no 13.146, de 6 de julho de 2015. Institui a Lei Brasileira de Inclusão da Pessoa com Deficiência (Estatuto da Pessoa com Deficiência). Diário Oficial [da] República Federativa do Brasil, Brasília.

Cafrune, M. E. (2016). O direito à cidade no Brasil: construçáo teórica, reivindicação e exercício de direitos. Revista Interdisciplinar de Direitos Humanos, 4(1), 185-206.

Cassapian, M. R., \& Rechia, S. (2014). Lazer para todos? Análise de acessibilidade de alguns parques de Curitiba, PR. Cadernos de Terapia Ocupacional da UFSCar, 22(1), 25-38. http://dx.doi.org/10.4322/cto.2014.004.

Castells, M. (2006). A questão urbana. São Paulo: Paz e Terra.

Cavalcanti, A., Alves, A. L., Vieira, A. F. R., Aramaki, A. K., \& Santana, A. P. S. (2013). Acessibilidade em transporte coletivo urbano na perspectiva dos motoristas e cobradores. Cadernos de Terapia Ocupacional da UFSCar, 21(1), 19-24. http://dx.doi.org/10.4322/cto.2013.004.

Christiansen, C. (1994). Classification and study in occupation a review and discussion of taxonomies. Journal of Occupational Science, 1(3), 3-20. http://dx.doi.org/10.1080/14427591.1994.9686382.

Constantinidis, T. C. (2012). "Cabeça vazia, oficina do diabo": concepçôes populares do termo ocupação e a terapia ocupacional. Psicologia e Sociedade, 24(3), 691-700. http://dx.doi.org/10.1590/S010271822012000300022.

Correia, R. L. (2017). Processos de ensinagem em desenvolvimento local participativo: a articulação comunitária e a produção do conhecimento fronteiriço enquanto capital social (Tese de doutorado). Faculdade de Medicina do ABC, Fundação do ABC, Santo André.

Correia, R. L. (2018a). Capital social colectivo entre personas mayores: la participación en ocupaciones colectivas como estrategias en terapia ocupacional en desarrollo local. Revista Chilena de Terapia Ocupacional, 18(1), 91-106. https://doi.org/10.5354/0719-5346.2018.48455.

Correia, R. L. (2018b). O alcance da terapia ocupacional no desenvolvimento local. Cadernos Brasileiros de Terapia Ocupacional, 26(2), 443-462. https://doi.org/https://doi.org/10.4322/2526-8910.ctoAO1182

Correia, R. L. (2019a). Processos de acessibilidade cultural participativa no ponto de cultura tradicional do Quilombo do Grotão (Monografia). Universidade Federal do Rio de Janeiro, Rio de Janeiro.

Correia, R. L. (2019b). Estratégias metodológicas sobre Leitura Comunitária em Planos Diretores Participativos de municípios brasileiros. São Paulo: Centro Universitário SENAC.

Correia, R. L., Akerman, M., \& Costa, S. L. (2016). Terapia ocupacional Social: un enfoque en desarrollo local participativo. Revista Terapéutica, 1, 28-32.

Correia, R. L., Costa, S. L., \& Akerman, M. (2017). Processos de ensinagem em desenvolvimento local participativo. Interaçōes, 18(3), 23. http://dx.doi.org/10.20435/inter.v18i3.1526.

Correia, R. L., Costa, S. L., \& Akerman, M. (2018). Processos de inclusão Quilombola nas políticas urbanas da cidade. Revista Interinstitucional Brasileira de Terapia Ocupacional, 2(4), 827-839.

Correia, R. L., \& Akerman, M. (2015). Desenvolvimento local participativo, rede social de suporte e ocupação humana: relato de experiência em projeto de extensão. Revista de Terapia Ocupacional da Universidade de São Paulo, 26(1), 159-165. https://doi.org/10.11606/issn.2238-6149.v26i1p159-165.

Costa, S. L., \& Alves, H. C. (2017). Diálogos Interepistêmicos: por uma terapia ocupacional de base alargada. Revisbrato - Revista Interinstitucional Brasileira de Terapia Ocupacional, 1(5), 527-532. 
Dorneles, P. S., \& Lopes, R. E. (2016). Cidadania e diversidade cultural na pauta das políticas culturais. Cadernos de Terapia Ocupacional da UFSCar, 24(1), 173-183. http://dx.doi.org/10.4322/01044931.ctoarf0669.

Dornelles, P., Carvalho, C., \& Castro, A. (2018). O curso de pós-graduação em acessibilidade cultural da Universidade Federal do Rio de Janeiro e suas ações de ensino, pesquisa e extensão. Revista da FAEEBA Educação e Contemporaneidade, 26(50), 105-117. http://dx.doi.org/10.21879/faeeba23580194.2017.v26.n50.p105-117.

Fernandes, E. (2005). Direito e gestão na construção da cidade democrática no Brasil. Oculum Ensaios, (4), 16-33.

Fernandes, E., \& Alfonsin, B. (2016). A construção do direito urbanístico na América Latina. Belo Horizonte: Gaia Cultural.

Ferreira, E. F. B., Folha, O. A. A. C., \& Tobias, M. S. G. (2013). Avaliação da percepçáo sobre o ambiente de circulaçáo: a acessibilidade centrada no usuário. Cadernos de Terapia Ocupacional da UFSCar, 21(1), 25-33. http://dx.doi.org/10.4322/cto.2013.005.

Freitas, E. L. H., \& Bueno, L. M. M. (2018). Processos participativos para elaboraçáo de Planos Diretores Municipais: inovações em experiências recentes. Urbe. Revista Brasileira de Gestão Urbana, 10(2), 304321. http://dx.doi.org/10.1590/2175-3369.010.002.ao09.

Galheigo, S. M. (2012). Perspectiva crítica y compleja de terapia ocupacional: actividad, cotidiano, diversidad, justicia social y compromiso ético-político. Revista de Terapia Ocupacional Galícia, 9(5), 176-189.

Galheigo, S. M., Braga, C. P., Arthur, M. A., \& Matsuo, C. M. (2018). Produção de Conhecimento, perspectivas e referências teórico-práticas na terapia ocupacional brasileira: marcos e tendências em uma linha do tempo. Cadernos Brasileiros de Terapia Ocupacional, 26(4), 723-738. https://doi.org/10.4322/2526-8910.ctoAO1773

Galvaan, R. (2015). The contextually situated nature of occupational choice: marginalised young adolescents" experiences in South Africa. Journal of Occupational Science, 22(1), 39-53. http://dx.doi.org/10.1080/14427591.2014.912124.

Gehl, J., \& Svarre, B. (2018). A vida na cidade: como estudar. São Paulo: Perspectiva.

Gomes, L., \& Emmel, M. L. G. (2016). Mapeamento da acessibilidade em edifícios públicos de cultura. Cadernos de Terapia Ocupacional da UFSCar, 24(3), 519-530. http://dx.doi.org/10.4322/01044931.ctoAO0741.

Gonçalves, M. V. (2020). A mobilidade urbana de jovens em projeto social do Complexo do Alemão, no Rio de Janeiro, e suas relaçôes com a terapia ocupacional social (Tese de doutorado). Universidade Federal de São Carlos, São Carlos.

Gonçalves, M. V., \& Malfitano, A. P. S. (2021). O conceito de mobilidade urbana: articulando açôes em terapia ocupacional. Cadernos Brasileiros de Terapia Ocupacional, 29, 1-13.

Gonçalves, M. V., \& Malfitano, A. P. S. (2020). Brazilian youth experiencing poverty: everyday life in the favela. Journal of Occupational Science, 27(3), 311-326. http://dx.doi.org/10.1080/14427591.2020.1757495.

Gonçalves, M. V., Bezerra Neto, L. R., \& Malfitano, A. P. S. (2020). O cotidiano revelado por imagens da cidade. Interface: Comunicação, Saúde, Educação, 24, 1-14. http://dx.doi.org/10.1590/interface.190418.

Hammell, K. W. (2009). Theories of Occupation. Canadian Journal of Occupational Therapy, 76(1), 6-13.

Harvey, D. (2012). O direito à cidade. Lutas Sociais, (29), 73-89.

Huff, S., Rudman, D. L., Magalhães, L., Lawson, E., \& Kanyamala, M. (2020). Enacting a critical decolonizing ethnographic approach in occupation-based research. Journal of Occupational Science, 27(4), 1-15. http://dx.doi.org/10.1080/14427591.2020.1824803.

Instituto Brasileiro de Geografia e Estatística - IBGE. (2010). Brasil. Recuperado em 03 de junho de 2019, de https://cidades.ibge.gov.br/brasil/panorama.

Instituto de Pesquisa Econômica Aplicada - IPEA. (2015). Atlas da Vulnerabilidade Social nos Municípios Brasileiros. Brasília: Ipea. 
Kantartzis, S., \& Molineux, M. (2017). Collective occupation in public spaces and the construction of the social fabric. Canadian Journal of Occupational Therapy, 84(3), 168-177.

http://dx.doi.org/10.1177/0008417417701936.

Kirzner, V. (2006). Planos Diretores Participativos: Balanço dos processos de elaboração e das temáticas emergentes - aplicaçáo dos instrumentos de democracia participativa durante o processo de elaboração e aprovação dos planos diretores. In Anais do $4^{\circ}$ Congresso Brasileiro de Direito Urbanístico (pp. 1-15). São Paulo: Instituto Brasileiro de Direito Urbanístico.

Law, M. (2002). Participation in the occupations of everyday life. The American Journal of Occupational Therapy, 56(6), 640-649. http://dx.doi.org/10.5014/ajot.56.6.640.

Léfèbvre, H. (2001). O direito à cidade. São Paulo: Centauro.

Ramugondo, E. L., \& Kronenberg, F. (2015). Explaining collective occupations from a human relations perspective: bridging the individual-collective dichotomy. Journal of Occupational Science, 22(1), 3-16. http://dx.doi.org/10.1080/14427591.2013.781920.

Ramugondo, E., Galvaan, R., \& Duncan, E. (2015). Theorising about human occupation. South African Journal of Occupational Therapy, 45(1), 1-2. https://doi.org/10.17159/2310-3833/2015/v45no1a1.

Reed, K., Smythe, L., \& Hocking, C. (2013). The meaning of occupation: A hermeneutic (Re)view of historical understandings. Journal of Occupational Science, 20(3), 253-261. http://dx.doi.org/10.1080/14427591.2012.729487.

Rolnik, R. (1995). O que é cidade. São Paulo: Brasiliense.

Rolnik, R., \& Pinheiro, O. M. (2004). Plano diretor participativo: guia para a elaboração pelos municípios e cidadãos. Brasília: CONFEA.

Rolnik, R. (2019). Guerra dos lugares: a colonização da terra e da moradia na era das finanças. São Paulo: Boitempo.

Santos, M. (2007). O espaço do cidadão. São Paulo: EdUSP.

Sarraf, V. P. (2018). Acessibilidade cultural para pessoas com deficiência: benefícios para todos. Revista do Centro de Pesquisa e Formação, (6), 23-43.

Saule Júnior, N., \& Uzzo, K. (2009). A trajetória da reforma urbana no Brasil. In A. Sugranyes \& C. Mathivet (Eds.), Ciudades para tod@s: Por el derecho a la ciudad, propuestas y experiências (pp. 261-272). Santiago: Habitat International Coalition.

Secretaria Municipal de Direitos Humanos e Cidadania - SMDHC. (2015). Cadernos de Formação. Direito à cidade. São Paulo: Instituto Paulo Freire.

Serpa, A. (2007). O espaço público na cidade contemporânea. São Paulo: Contexto.

Silva, A. C. C., \& Oliver, F. C. (2019). Participação social em terapia ocupacional: sobre o que estamos falando? Cadernos Brasileiros de Terapia Ocupacional, 27(4), 858-872. https://doi.org/https://doi.org/10.4322/2526-8910.ctoAR1883.

Simaan, J. (2020). Decolonising occupational science education through learning activities based on a study from the Global South. Journal of Occupational Science, 27(3), 432-442. http://dx.doi.org/10.1080/14427591.2020.1780937.

Sobel, R. (1993). From occupational involvement to political participation: an exploratory analysis. Political Behavior, 15(4), 339-353. http://dx.doi.org/10.1007/BF00992102.

Tolvett, P. (2016). Vida cotidiana y ocupación : reflexiones desde espacios formativos Conceptualizations of culture, socialization, daily life. Revista Ocupación Humana, 16(1), 56-69.

Trindade, T. A. (2012). Direitos e cidadania: reflexôes sobre o direito à cidade. Lua Nova, (87), 139-165. https://doi.org/http://dx.doi.org/10.1590/S0102-64452012000300007

Vessby, K., \& Kjellberg, A. (2010). Participation in occupational therapy research: A literature review. British Journal of Occupational Therapy, 73(7), 319-326. http://dx.doi.org/10.4276/030802210X12759925544380.

Vieira Filho, P. R. D. S., Gonçalves, M. V., \& Takeiti, B. A. (2020). Os significados e experiências do "Projeto Juventude(S)". Revista Interinstitucional Brasileira de Terapia Ocupacional, 4(2), 137-143. https://doi.org/10.47222/2526-3544.rbto31030 


\section{Contribuiçáo dos Autores}

Ambos os autores foram responsáveis pela concepção, escrita e revisão do manuscrito e aprovaram sua versão final.

\section{Autor para correspondência}

Ricardo Lopes Correia. E-mail: toobiis@gmail.com

\section{Editora de seçáo}

\section{Profa. Dra. Daniela Tavares Gontijo}

